\title{
Neuropsychological effects and attitudes in patients following electroconvulsive therapy
}

\author{
Miriam Feliu' ${ }^{1,2}$ \\ Christopher L Edwards',2,3 \\ Shiv Sudhakar ${ }^{4}$ \\ Camela McDougald' \\ Renee Raynor ${ }^{5}$ \\ Stephanie Johnson ${ }^{6}$ \\ Goldie Byrd ${ }^{7}$ \\ Keith Whitfield 8 \\ Charles Jonassaint ${ }^{8}$ \\ Heather Romero' \\ Lekisha Edwards' \\ Chante' Wellington' \\ LaBarron $\mathrm{K} \mathrm{Hill}^{9}$ \\ James Sollers, III ${ }^{9}$ \\ Patrick E Logue' \\ 'Department of Psychiatry \\ and Behavioral Sciences; ${ }^{2}$ Duke \\ Pain and Palliative Care Center; \\ ${ }^{3}$ Department of Medicine, Division \\ of Hematology; ${ }^{4}$ Drexel University \\ Medical School; ${ }^{5}$ Brain Tumor \\ Center, Duke University Medical \\ Center, Durham, NC, USA; ${ }^{6}$ Science \\ Directorate, American Psychological \\ Association; 'Department of Biology, \\ North Carolina A\&T State University; \\ ${ }^{8}$ Department of Psychology, \\ Duke University; ${ }^{9}$ Department \\ of Psychology, The Ohio State \\ University
}

Correspondence: Christopher L Edwards Medical Director, Biofeedback Laboratory and Pediatric Neuropsychology Service; Director, Chronic Pain Management Program, Duke University Medical Center, 932 Morreene Rd., Rm I70, Durham, NC 27705, USA

Tel + I 9196846908

Fax $+|91966828| 1$

Email christopher.edwards@duke.edu

\begin{abstract}
The current study examined the effects of electroconvulsive therapy (ECT) on neuropsychological test performance. Forty-six patients completed brief neuropsychological and psychological testing before and after receiving ECT for the treatment of recalcitrant and severe depression. Neuropsychological testing consisted of the Levin Selective Reminding Test (Levin) and Wechsler Memory Scale-Revised Edition (WMS-R). Self-report measures included the Beck Depression Inventory (BDI), the Short-Term Memory Questionnaire (STMQ), and several other measures of emotional functioning and patient attitudes toward ECT. The mean number of days between pre-ECT and post-ECT testing was 24. T-test revealed a significant decrease in subjective ratings of depression as rated by the BDI, $\mathrm{t}(45)=9.82, \mathrm{P}<0.0001$ (Pre$\mathrm{BDI}=27.9 \pm 20.2$; post-BDI $=13.5 \pm 9.7)$. Objective ratings of memory appeared impaired following treatment, and patients' self-report measures of memory confirmed this decline. More specifically, repeated measures MANOVA [Wilks Lambda $\mathrm{F}(11,30)=4.3, \mathrm{p}<0.001$ ] indicated significant decreases for measures of immediate recognition memory $(p<0.005)$, long-term storage $(\mathrm{p}<0.05)$, delayed prose passage recall $(\mathrm{p}<0.0001)$, percent retained of prose passages $(p<0.0001)$, and percent retained of visual designs $(p<0.0001)$. In addition, the number of double mentions on the Levin increased $(\mathrm{p}<0.02$ ). This study suggests that there may be a greater need to discuss the intermittent cognitive risks associated with ECT when obtaining informed consent prior to treatment. Further that self-reports of cognitive difficulties may persist even when depression has remitted. However, patients may not acknowledge or be aware of changes in their memory functioning, and post-ECT self-reports may not be reliable.
\end{abstract}

Keywords: electroconvulsive therapy, neuropsychology, attitudes, memory

\section{Introduction}

Electroconvulsive therapy (ECT) remains a widely used efficacious treatment for a variety of complicated psychiatric conditions, particularly affective disorders resistant to psychotherapy, medication, and other forms of treatment (Chamberlin and Tsai 1998; Rami-Gonzalez et al 2001). Specifically, ECT has been found to decrease symptoms associated with intractable depression (Neylan et al 2001; Taieb et al 2001) but sometimes at the temporary cost of decreased speed of information processing (Tsourtos et al 2007).

Despite the noted success of this medical procedure in terms of decreasing depression, several cognitive side effects have been noted. These include an acute confused state immediately following the procedure, postictal delirium, interictal disorientation, and anterograde and retrograde memory disturbances (Durr and Golden 1995). The most notable cognitive side effect has been an iatrogenic form of transient amnesia, similar to that caused by anticholinergic drugs (Kopelman 1986; Kopelman and Corn 1988) and benzodiazepines (Curran 1991, 1986).

The adverse effects of ECT on cognitive functioning, particularly memory, are typically more pronounced and have been known for some time (Janis and Astrachan 
1951; Hihn et al 2006; Fujita et al 2006) However, there is still controversy regarding the impact these memory difficulties may have, as some regard them as limited and tolerable (Abraham et al 2006). Several hypotheses have been set forth to address the controversy. The changes in cognitive decline have been attributed to decreases in hippocampal volume (Lekwauwa et al 2006), which may vary depending upon electrical waveform and electrode placement (Sackeim et al 2007), as well as the type of induction agents (Larsen et al 2005). In contrast, animal models have suggested the differences in gene expression may influence cognitive decline post-ECT (McDaniels et al 2006). Others suggest that social stigma surrounding ECT may limit its use, effectiveness, and compromise scientific exploration that may aid in determining the mechanisms associated with cognitive decline (Melding 2006).

Squire (1977) investigated the effects of ECT on cognitive functioning and found that bilateral ECT produced greater anterograde memory loss than right unilateral ECT on both recall and recognition memory tests. In addition, bilateral ECT was associated with more extensive retrograde amnesia than unilateral ECT and that the capability to form new memories substantially recovered 6-9 months after unilateral ECT. Unfortunately, continued memory complaints were common among individuals who received bilateral ECT. Several other studies have revealed similar long-term consequences of ECT (Weeks et al 1980; Frith et al 1983; Squire et al 1984; Sackeim 1992; Sackeim et al 2007).

Despite a relatively complete recovery of memory functioning several months following ECT in a majority of patients, many individuals complain of continued memory deficits 3 years or more after treatment. However, these complaints may be due to a lack of improvement in depressive symptoms. Several researchers have found that ECT patients who continue to experience depressive symptoms complain of more memory loss as compared with their counterparts whose depressive symptoms go into remission, but do not demonstrate memory deficits on neuropsychological evaluation (Freeman et al 1980; Squire and Slater 1983; Frith et al 1983). Furthermore, depressive symptoms or medication were not associated with deficits on tests of logical memory, face-name recall and verbal learning (Freeman et al 1980). This suggests that depressive symptoms may have an influence on self-report cognitive deficits but are not associated with neurocognitive testing performance.

More recent empirical evidence suggests that patients report improvements in cognitive functioning post-ECT. Coleman and colleagues (1996) found that, at baseline, patients reported marked deficits on a self-report measure of memory functioning. However, these patients reported improved memory functioning shortly following ECT, despite objective test results indicating impaired anterograde and retrograde memory deficits at that time. Improvements in self-reported memory functioning were less pronounced among patients who received high dosage ECT stimulation and/or bilateral electrode placement. In contrast to previous literature, this evidence suggests that low dosage ECT, and to some extent, high dosage ECT may be associated with increased self-report memory functioning. Coleman and colleagues (1996) suggested that this difference might reflect the changes in ECT practices. Despite the positive implications of the Coleman and colleagues' (1996) findings, more evidence is needed to support the positive effects of ECT on self-report memory functioning.

The purpose of the present study was to investigate the relationship between self-reported memory functioning, objective measures of memory functioning, and self-reported mood. The study further will provide evidence for memory functioning of patients prior to and after receiving ECT.

\section{Method \\ Design}

Using archival methods, we reviewed the medical records of 46 sequential patients seen at a southeastern USA medical facility for neuropsychological evaluation prior to and after ECT.

\section{Participants}

All participants were referred with a primary diagnosis of major depression, recurrent, severe without psychotic features $(\mathrm{N}=46)$. Of the 46 participants (30 females), 40 completed the neuropsychological evaluation as inpatients at the hospital. The vast majority of participants were Caucasian $(\mathrm{N}=44)$, the mean age was 56.2 years $(\mathrm{SD}=17.32$; range $19-96)$, and the mean years of education was $13.6(\mathrm{SD}=3.2)$. The mean number of days between the pre- and post-ECT neuropsychological evaluations was 24.5 days $(\mathrm{SD}=11.4)$.

\section{Clinical assessment instruments}

\section{and procedures}

All participants completed neuropsychological tests consisting of the Short-Term Memory Questionnaire (STMQ; Koss et al 1993), Levin Selective Reminding Test (Levin: Hannay \& Levin 1985), and the Logical Memory and Visual Reproduction subtests from the Wechsler Memory Scale (WMS-R) on the day prior to ECT. Psychological tests included the Beck 
Depression Inventory (BDI) and several other self-report measures of emotional functioning and patient attitudes toward ECT.

\section{Results}

For the current analyses, we utilized a set of simple parametric procedures to detect difference in means as a function of their standard deviations, and the total sample size. Simple 2 group comparisons were made using T-tests. Multivariate analysis of variance was used to evaluate the simultaneous effects of time on multiple dependent variables. Due to limited sample size, we did not utilize models of covariance for age and other demographic factors in the current analyses.

T-test revealed a significant decrease in subjective ratings of depression as rated by the BDI, $\underline{\mathrm{t}}(45)=9.82, \mathrm{p}<0.0001$. Table 1 presents the means on the BDI. A repeated measures MANOVA indicated a significant effect of time on neuropsychological measures of verbal and visual memory, Wilks Lambda $\underline{\mathrm{F}}(11,30)=4.3, \mathrm{p}<0.001$. On a verbal list-learning test (Levin), there was a significant decrease in long-term storage and immediate recognition memory following ECT. A significant increase in the number of repetitions on the Levin was noted. Similarly, delayed recall and percent retained for paragraph length were significantly decreased after ECT (p-values; or effect size). With respect to visual memory, the percent retained for geometric designs was also significantly decreased following ECT. Tables 2 and 3 present the results for the neuropsychological measures.

Patients' self-report of memory functioning after ECT was somewhat inconsistent. On the Short-term Memory Questionnaire (SMQ), patients did not report a significant change in their memory functioning after ECT $(\mathrm{p}>0.35)$. The SMQ means presented in Table 4 are consistent with previous results (Koss et al 1993) which indicate memory deficits, although not to a level of mild dementia. Differences between pre- and post-ECT were observed on another self-report measure that asked patients to rate memory impairments on a temporal gradient that ranged from 10 minutes ago to 21-30 years ago. On this measure, patients indicated poorer short-term memory (those events which occurred 10 minutes ago) and long-term memory (those

Table I Beck Depression Inventory score pre- and post-ECT

\begin{tabular}{lll}
\hline Variable & Mean (SD) & Range \\
\hline Pre-ECT raw score & $27.9(20.2)$ & $20-62$ \\
Post-ECT raw score & $13.5(9.7)$ & $0-39$ \\
\hline
\end{tabular}

Abbreviation: ECT, electroconvulsive therapy.
Table 2 Levin Selective Reminding Test scores pre- and post-ECT

\begin{tabular}{llll}
\hline Variable & $\begin{array}{l}\text { Pre-ECT } \\
\text { Mean (SD) }\end{array}$ & $\begin{array}{l}\text { Post-ECT } \\
\text { Mean (SD) }\end{array}$ & p value \\
\hline $\begin{array}{l}\text { Long-term storage } \\
\begin{array}{l}\text { Consistency of long-term } \\
\text { storage }\end{array}\end{array}$ & $\begin{array}{l}27.4(18.6) \\
18.4(17.6)\end{array}$ & $\begin{array}{l}21.4(14.4) \\
\text { I } 3.1(11.5)\end{array}$ & NS \\
$\begin{array}{l}\text { Immediate recognition } \\
\text { memory }\end{array}$ & $10.1(5.6)$ & $9.7(2.3)$ & $0.0 \mathrm{I}$ \\
$\begin{array}{l}\text { Intrusions } \\
\text { Double mentions }\end{array}$ & $1.6(2.5)$ & $1.2(1.4)$ & $\mathrm{NS}$ \\
\hline
\end{tabular}

Abbreviation: ECT, electroconvulsive therapy.

Table 3 Wechsler Memory Scale scores pre- and post-ECT

\begin{tabular}{llll}
\hline Variable & $\begin{array}{l}\text { Pre-ECT } \\
\text { Mean (SD) }\end{array}$ & $\begin{array}{l}\text { Post-ECT } \\
\text { Mean (SD) }\end{array}$ & p Value \\
\hline Immediate verbal memory & $14.9(6.5)$ & $14.6(6.0)$ & NS \\
$\begin{array}{l}\text { Delayed verbal memory } \\
\text { \% Retained for verbal }\end{array}$ & $10.4(6.6)$ & $6.9(6.7)$ & $0.00 \mathrm{I}$ \\
memory & $64.1(27.3)$ & $40.8(28.2)$ & 0.001 \\
$\begin{array}{l}\text { Immediate visual memory } \\
\text { Delayed visual memory }\end{array}$ & $6.4(4.0)$ & $6.9(4.3)$ & $\mathrm{NS}$ \\
\% Retained for visual memory & $72.4(3.8)$ & $4.2(3.9)$ & $\mathrm{NS}$ \\
\hline
\end{tabular}

Abbreviation: $\mathrm{ECT}$, electroconvulsive therapy.

Table 4 Means for the Short-Memory Questionnaire

\begin{tabular}{ll}
\hline & Mean (SD) \\
\hline Pre-ECT & $39.7(8.3) \mathrm{ns}$ \\
Post-ECT & $41.6(7.3) \mathrm{ns}$ \\
\hline
\end{tabular}

Abbreviation: $\mathrm{ECT}$, electroconvulsive therapy.

events which occurred one month ago) functioning. These findings were confirmed with significant decreases on global self-report measures of memory dysfunction in the past week $(\mathrm{p}<0.03)$.

Nonparametric analysis (Wilcoxon Signed Ranks Test) revealed that patients' attitudes towards ECT changed after completing their treatments. Specifically, patients rated ECT to be more effective than drugs $(\mathrm{p}<0.005)$ in treating their depression.

\section{Discussion}

The results of this study support the findings of previous research indicating that ECT results in decreased memory functioning. The results of the current study indicate relatively immediate and significant decreases in multiple areas of memory following ECT compared with pre-ECT levels of functioning including verbal memory for word lists and prose passages and visual memory of geometric designs. 
Contrary to the established literature, patients indicated memory deficits both before and after receiving ECT, but did not report a significant change in their subjective ratings of memory functioning. Indeed, there was a slight trend towards improved memory functioning, despite the objective neuropsychological data indicating significantly lower recognition and delayed recall. Thus, self-appraisal of memory functioning seems to be impacted and should be further explored to better understand these findings. As expected, patients self-reported levels of depression were significantly lower following ECT. Thus, the results indicate that ECT was successful in alleviating depressive symptomatology while cognitive deficits persisted with poor insight of cognitive decline post ECT.

The current results stress the need for providing a significant level of informed consent to patients prior to receiving ECT and the need for additional efforts to assure that written information is comprehended (Edwards and Rogers 2007). This need is further argued when considering ECT for older adults. For instance, the implications of such memory changes associated with an older adults' real-world functioning should be discussed, particularly if the patient is living independently. Perhaps, development of compensatory strategies should be implemented to assist the patient as they recover following such treatment (ie, using post-it-notes, family assistance, reminders, pill box, calendars, etc). This may help to reduce or minimize potential risks for other problems (ie, forgetting to take medications for medical problems, safety, etc).

Durr and Golden (1995) purport that this is particularly important to consider when older adults with preexisting cognitive or neurological dysfunction are at greater risk of cognitive disturbances resulting from ECT. Consideration of use of medications and behavioral techniques that reduce the impact of ECT on memory should be considered (Prakash et al 2006; MacQueen et al 2007). When ECT is provided to adolescents, the potential impact of such cognitive changes should be discussed with the patients and their parents or guardians in terms of implications for not only the patient's emotional functioning but cognitive functioning as well, particularly upon his or her academic performance. In summary, we argue that an individual cost-benefit analysis should be made in light of the implications of the potential benefits versus costs of ECT upon improving emotional functioning and the impact that potential memory changes may have on real-world functioning and quality of life.

The archival nature of the current methodology serves as a potential limitation to this study. For example, our ability to collect data on medications and evaluate the influence of these medications on mood and memory at the time of intervention was extremely limited due to the retrospective nature of the data collection. Further, data about the technical parameters of the ECT procedure (mean seizure length, electrode placement, etc) were not available to us at the time of the review. However, archival methodology can facilitate documentation of observed phenomena in a fashion that promotes the development of future prospective studies. We view the value of the current study in such a context.

We also recognize that our limited sample size could be of concern to some readers. More specifically, we utilized conservative techniques to model relationships between variables and to control for factors that could account for additional variance in our analyses. We view this as a reasonable trade-off to document the current finding and inspire new science related to the cognitive affects of ECT. Although we noted at least one statistically significant finding in our results that was not equally clinically meaningful, we believe that highlighting differences between subjective appraisals and objective measures of memory have clinical significance. We also note published studies in the ECT literature that are equally plagued with this common issue but contributing to our knowledge of the impact of ECT on cognitive factors (Datka et al 2007).

Future research should focus on delineating specific cognitive changes associated with the use of ECT in different age groups, the time course to recovery and identifying recommendations and appropriate strategies to compensate for temporary cognitive changes upon discharge and to promote insight into such decline (Blaj et al 2007). These results follow some recommendations (Neylan et al 2001) which argue that the identification of risk factors for ECT-related cognitive side effects need to be better characterized in an effort to assist clinicians with informing patients of such risks and to potentially implement prophylactic interventions. These results also urge for continued research in the area of ECT and neurocognitive changes to identify patient-specific factors that may contribute to ECT-induced cognitive impairment.

\section{Disclosure}

The authors report no conflicts of interest.

\section{References}

Abraham G, Milev R, Delva N, et al. 2006. Clinical outcome and memory function with maintenance electroconvulsive therapy: a retrospective study. J ECT, 22:43-5.

Blaj A, Worrall A, Chaplin R. 2007. Electroconvulsive therapy: the practice and training needs of referring psychiatrists in the United Kingdom and Republic of Ireland. J ECT, 23:78-81. 
Chamberlin E, Tsai GE. 1998. A glutamatergic model of ECT-induced memory dysfunction. Harv Rev Psychiatry, 5:307-17.

Coleman EA, Sackeim HA, Prudic J, et al. 1996. Subjective memory complaints prior to and following electroconvulsive therapy. Biol Psychiatry, 39:346-56.

Curran HV. 1991. Benzodiazepines, memory, and mood: A review. Psychopharmacology, 105:1-8.

Curran HV. 1986. Tranquillizing memories: A review of the effects of benzodiazepines on human memory. Biological Psychol, 23:179-213.

Datka W, Siwek M, Dudek D, et al. 2007. Working memory disturbances in patients with major depression after ECT treatment. Psychiatria Polska, 41:339-49.

Durr AL, Golden RN. 1995. Cognitive effects of electroconvulsive therapy: A clinical review for nurses. Convuls Ther, 11:192-201.

Edwards CL, Rogers L. 2007. Literacy as the foundation of patient responsibility. J Pain, 8:824-5.

Freeman CL, Weeks D, Kendell RE. 1980. Electroconvulsive therapy. Br J Psychiatry, 137:8-37.

Frith CD, Stevens M, Johnstone EC, et al. 1983. Effects of ECT and depression on various aspects of memory. Br J Psychiatry, 142:610-17.

Fujita A, Nakaaki S, Segawa K, et al. 2006. Memory, attention and executive functions before and after sine and pulse wave electroconvulsive therapies for treatment-resistant major depression. $J E C T, 22: 107-12$.

Hannay HJ, Levin HS. 1985. Selective Reminding Test: An examination of the equivalence of four forms. J Clin Exper Neuropsychol, 7:251-63.

Hihn H, Baune BT, Michael N, et al. 2006 Memory performance in severely depressed patients treated by electroconvulsive therapy. $J E C T, 22: 189-95$.

Janis IL, Astrachan M. 1951. The effects of electroconvulsive treatments on memory efficiency. J Abnorm Soc Psychol, 46:501-11.

Kopelman MD, Corn TH. 1988. Cholinergic "blockade" as a model for cholinergic depletion: A comparison of the memory deficits with those of Alzheimer-type dementia and alcoholic Korsakoff syndrome. Brain, 111:1079-110.

Kopelman MD. 1986. The cholinergic neurotransmitter system in human memory and dementia: A review. Exp Psychol, 38:535-73.

Koss E, Patterson M, Ownby R, et al. 1993. Memory evaluation in Alzheimer's Disease. Arch Neurol, 50:92-7.

Larsen MH, Olesen M, Woldbye DP, et al. 2005. Regulation of activityregulated cytoskeleton protein (Arc) mRNA after acute and chronic electroconvulsive stimulation in the rat. Brain Res, 1064(1-2):161-5.
Lekwauwa R, McQuoid D, Steffans DC. 2006. Hippocampal volume is associated with physician-reported acute cognitive deficits after electroconvulsive therapy. J Geriatr Psychiatry Neurol, 19:21-5.

McDaniel WW, Sahota AK, Vyas BV, et al. 2006. Ketamine appears associated with better word recall than etomidate after a course of 6 electroconvulsive therapies. $J E C T, 22: 103-6$.

MacQueen G, Parkin C, Marriott M, et al. 2007. The long-term impact of treatment with electroconvulsive therapy on discrete memory systems in patients with bipolar disorder. J Psychiatry Neurosci, 32:241-9.

Melding P. 2006. Electroconvulsive therapy in New Zealand: terrifying or electrifying? N Z Med J, 119(1237):U2051.

Neylan TC, Canick JD, Hall SE, et al. 2001. Cortisol levels predict cognitive impairment induced by electroconvulsive therapy. Biol Psychiatry, 50:331-6.

Prakash J, Kotwal A, Prabhu H. 2006. Therapeutic and prophylactic utility of the memory-enhancing drug donezepil hydrochloride on cognition of patients undergoing electroconvulsive therapy: a randomized control trial. JECT, 22:163-8.

Sackeim HA. 1992. The cognitive effects of electroconvulsive therapy. In: Moos WH, Gamzu ER, Thal LJ (eds). Cognitive disorders: pathophysiology and treatment. New York: Marcel Dekker, pp. 183-228.

Sackeim HA, Prudic J, Fuller R, et al. 2007. The cognitive effects of electroconvulsive therapy in community settings. Neuropsychopharmacology, 32:244-54.

Squire LR. 1977. ECT and memory loss. Am J Psychiatry, 134:997-1001.

Squire LR, Cohen NJ, Nadel L. 1984. The medial temporal region and memory consolidation: A new hypothesis. In: Weingartner H. Parker E (eds). Memory consolidation. Hillsdale, NJ: Erlbaum Associates.

Squire LR, Slater PC. 1983. ECT and complaints of memory dysfunction: A prospective three-year follow-up study. Br J Psychiatry, 142:1-8.

Taieb O, Flament MF, Corcos M, et al. 2001. Electroconvulsive therapy in adolescents with mood disorder: Patients' and parents' attitudes. Psychiatr Res, 104:183-90.

Tsourtos G, Spong J, Stough C. 2007. The effects of electro-convulsive therapy on the speed of information processing in major depression. $J$ Affect Disord, 103(1-3):263-6.

Weeks D, Freeman CP, Kendall RE. 1980. ECT, 3: Enduring cognitive deficits. Br J Psychiatry, 137:26-37. 
